\title{
DENTAL FLUOROSIS AND CARIES STATUS AMONG 12-13 YEAR-OLD SCHOOLCHILDREN IN KLANG DISTRICT, MALAYSIA
}

R. Esa, I. A. Razak. Dental fluorosis and caries status among 12-13 year-old schoolchildren in Klang District, Malaysia. Annal Dent Univ Malaya 2001; 8: 20-24.

\section{ABSTRACT}

Several national studies have been undertaken to assess the prevalence of fluorosis utilizing the Dean's Index. However, the latest national study undertaken in 1997 (1) had utilized the DDE Index and hence does not allow comparisons to be made with the earlier set of national data. This cross-sectional study was undertaken to evaluate the prevalence of dental fluorosis using the Dean's Index in a sample of 12-13 year-old schoolchildren and to assess the relationship between fluorosis and their caries status. The sampling procedure involved a multistage, clustered and stratified random sampling. The sample comprised of 1519 schoolchildren attending 20 secondary government and governmentaided schools in fluoridated urban and rural areas of Klang District in Peninsular Malaysia. There were 772 males and 747 females. Each subject was administered a questionnaire to elicit the demographic information. Intra-oral examination for dental fluorosis and caries was performed for each subject. The results demonstrated that more than half of the subjects (54\%) had no fluorosis, $13.2 \%$ had questionable fluorosis, $31.3 \%$ had very mild to mild fluorosis, $1.4 \%$ had moderate fluorosis and only $0.1 \%$ exhibited severe fluorosis. The mouth prevalence was $32.8 \%$. The Community Fluorosis Index was 0.48 indicating a borderline score for public health significance. Fifty-two percent of the children were caries free. The mean DMFT for all subjects was 1.1, $\mathrm{F}(0.6)$ being the main component. Although girls had a higher mean DMFT score as compared to boys this difference was not significant. Significant differences in DMFT scores were observed by urban/ rural distributions and ethnic groups $(\mathrm{p}<0.01)$. No significant correlation was found between fluorosis and caries status. It is concluded that dental fluorosis does not appear to be a public health problem. Further coordinated in-depth research using similar criterias for assessing dental fluorosis is highly recommended.

\section{INTRODUCTION}

The prevalence of dental or enamel fluorosis especially mild fluorosis has been increasing in a number of countries in recent years (2-7). Although this increase is well documented elsewhere, local data is lacking to reflect the present scenario. A recent study conducted on 16-year-old schoolchildren reported that the mouth prevalence for enamel defects was $56 \%$ according to the
Original Article

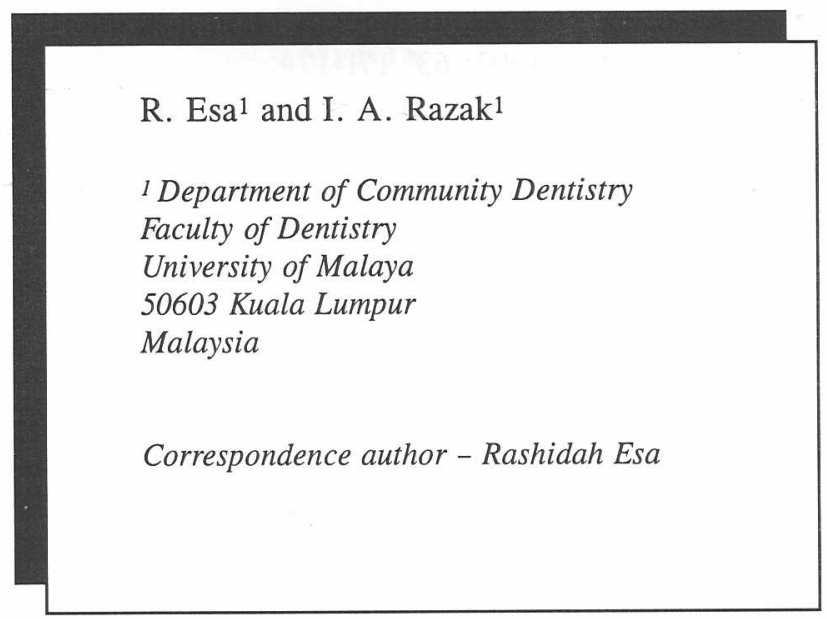

DDE Index, of which $67.4 \%$ was of the diffuse type (1). Earlier, other studies had indicated prevalences of over $70 \%$ employing similar index (8-12). The National Epidemiological surveys conducted on schoolchildren using the Dean's Index recorded a prevalence of $7.8 \%$ for the 12 -year-old children in Peninsular Malaysia and between $21-25 \%$ in Sabah for 12-13 year-olds $(13,14)$.

Concurrently, the prevalence of dental caries is declining in Malaysia, which was apparent between 1976 and 1985 after the widespread water fluoridation programme and the availability of the fluoridated toothpaste in the market (15). A series of descriptive epidemiological surveys to assess the oral health status of schoolchildren have been conducted by the Oral Health Division, Ministry of Health over the last few decades $(1,13,16)$. The dental caries prevalence for the 12-year-olds in Peninsular Malaysia declined from $78.4 \%(1970 / 71)$ to $71.3 \%(1988)$ to $57.1 \%$ (1997). Caries experience for the same age group also declined from a mean DMFX(T) of 3.7 (1970/71) to 2.37 (1988) to 1.6 (1997) in Peninsular Malaysia. However caries prevalence and experience remains high for the 12-yearold schoolchildren in Sabah and Sarawak $(14,17,18)$. This may be associated with late efforts at implementing fluoridation programmes in Sabah and the geographical inaccessability for optimum coverage in Sarawak (1).

There is a rising concern from the public over the effects of fluoride usage either from the drinking water as well as from the toothpaste. The fluoridation of public water supply in Malaysia began 3 decades ago. The beneficial effects of fluoride cannot be denied in reducing caries, however constant monitoring of fluoride exposures in the population is necessary to attain public's confidence. This study was undertaken to evaluate the prevalence of dental fluorosis in a sample of 12-13 year-old schoolchildren utilising the Dean's Index for fluorosis, and to assess the relationship between fluorosis and caries status. 


\section{MATERIALS AND METHODS}

The subjects were 1519 secondary schoolchildren between the ages of 12 and 13 from urban and rural areas in Klang District, one of the largest and most populous districts in Malaysia. Both these areas and populations have been exposed to more than 20 years of water fluoridation and a well established school dental service including both curative, preventive and health education programmes.

The sampling procedure involved a multistage, clustered and stratified sampling. Twenty schools were selected from both urban and rural areas according to geographic location and type of school. Eligible children were selected randomly from a list obtained from school records. Age eligibility requires that the subjects fall into the appropriate age domain at the time of sampling. Approval to conduct the study was obtained from the Ministry of Education, the State School Director and the Principals of all participating schools.

All examinations for fluorosis and dental caries status were performed by one examiner (RE) with the use of a plain mouth mirror, probe and fibre optic light for caries. Teeth were not dried prior to fluorosis examination which was carried out under natural light. The clinical examination criteria employed was the Dean's Index for fluorosis and the DMF Index for caries (19). The data for each subject was recorded on a standard WHO form by the trained research assistant. A self-administered questionnaire survey was conducted to elicit information regarding the name, age, school (urban/rural), gender and ethnic origin of the subjects. In addition, water samples from each school were collected to ascertain the level of fluoride using a fluoride spectrometer in the laboratory. The fluoride level of drinking water in the urban and rural schools were found to be $0.74 \pm 0.31$ and $0.45 \pm 0.23$ parts per million respectively.

Calibration exercises to assess intra-examiner reliability were conducted for dental fluorosis and dental caries prior to the survey and also during the survey. The total number of children re-examined was 75 , which was about $5 \%$ of the total sample. The level of reproducibility was expressed using the kappa statistic (20). The data collected were analysed using SPSS-PC + programme. The Spearman Correlation test was used to establish the association between fluorosis and caries status. In addition analysis of variance between the mean DMF and sociodemographic factors were established using the Mann-Whitney U test for gender and residence and Kruskal-Wallis test for ethnic groups. The significance level for all the analysis was set at $\mathrm{P}<0.05$.

\section{RESULTS}

A total of 1519 students (out of 6254 students) of 12-13 year age group participated in this study. Seven subjects who were wearing full-band orthodontic appliance were excluded. Table 1 shows the distribution of subjects by gender, ethnic group and residence. There was almost equal proportion of subjects by gender. The proportion of Malay and Chinese subjects were almost similar. There were more urban subjects as compared to the rural $(1.7: 1)$. The distribution of subjects in this sample is representative of the population in Klang district.

Intra-examiner agreement for enamel fluorosis was conducted prior to data collection and during the survey. The kappa value obtained when five per cent of the subjects were re-examined during the survey was $k=$

Table 1. Distribution of subjects and Dental Caries Status: Mean DMFT by Gender, Ethnic groups and Residence

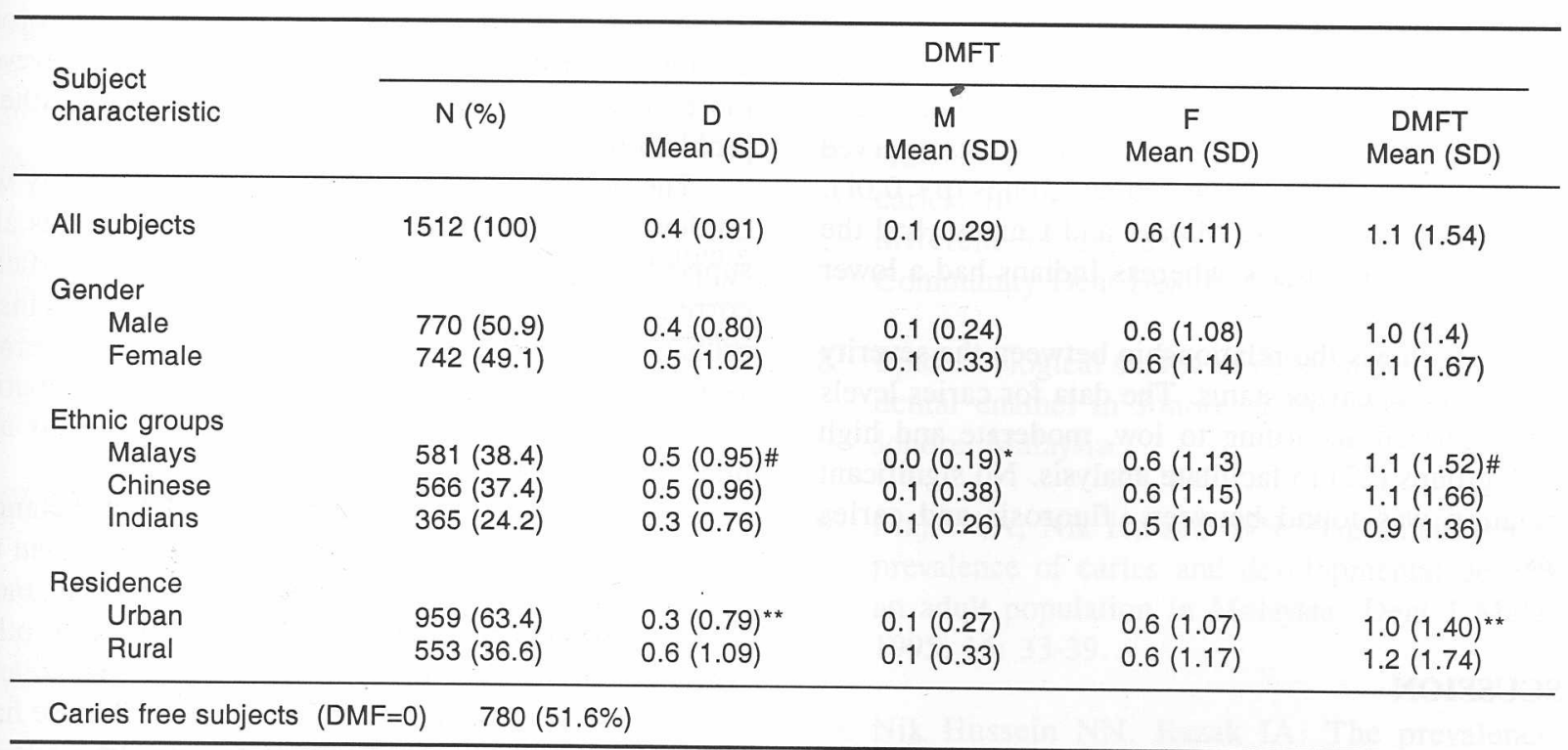

\# Significant for Malays and Indians, Chinese and Indians $p<0.01$

* Significant for Malays and Chinese, Malays and Indians $p<0.01$

** Significant $\mathrm{p}<0.01$ 
Table 2. Distribution of DEAN'S FLUOROSIS INDEX scores

\begin{tabular}{lrcc}
\hline & Number & Per cent & $\begin{array}{c}\text { Frequency } \times \\
\text { weight }\end{array}$ \\
\hline Normal & 817 & 54.0 & 0 \\
Questionable & 200 & 13.2 & 100 \\
Very mild & 389 & 25.7 & 389 \\
Mild & 84 & 5.6 & 168 \\
Moderate & 21 & 1.4 & 63 \\
Severe & 1 & 0.1 & 4 \\
\hline TOTAL & 1512 & & 724 \\
MOUTH & 495 & 32.8 & \\
PREVALENCE & & & \\
\hline
\end{tabular}

Community Fluorosis Index $(\mathrm{CFI})=724 / 1512=0.48^{*}$

As defined by Dean 1935

* Borderline

0.80. The kappa values for dental caries status obtained before and during the data collection period were high $(k=0.90)$.

The distribution of dental fluorosis scores for all subjects is depicted in Table 2. Of all the children examined, 817 (54.0\%) did not have fluorosis, 200 (13.2\%) had questionable fluorosis, 389 (25.7\%) had very mild fluorosis, $84(5.6 \%)$ had mild fluorosis. The proportion of subjects with moderate $(21$ or $1.4 \%)$ and severe $(1$ or $0.1 \%$ ) fluorosis were low. The mouth prevalence for this sample was therefore $32.8 \%$. The Community Fluorosis Index (CFI) was derived by multiplying the numerical weight and the frequency of fluorosis and dividing it by the total sample (21). The CFI for this sample was 0.48 indicating a borderline score for public health significance.

Table 1 shows the dental caries status (mean DMFT) by gender, ethnic groups and residence. About $52 \%$ of the children were caries free indicating a prevalence of $48 \%$ for dental caries. The mean DMFT for all subjects was 1.1(SD1.5), $F(0.6)$ being the main component. Although girls had a higher mean DMFT score as compared to boys this difference was not significant. Significant differences in DMFT scores were observed by urban/rural distributions and ethnic groups $(\mathrm{p}<0.01)$. For the ethnic groups the Malays and Chinese had the same DMFT score of 1.1 whereas Indians had a lower score of 0.9 .

Table 3 shows the relationship between the severity of fluorosis and caries status. The data for caries levels was categorized according to low, moderate and high DMFT groups (22) to facilitate analysis. No significant correlation was found between fluorosis and caries status.

\section{DISCUSSION}

Most of the recent local studies on enamel defects had employed the Developmental Defects of Enamel (DDE) index (23). This index being descriptive does not attempt
Table 3. Relationship between fluorosis and caries status

\begin{tabular}{lccc}
\hline \multirow{2}{*}{ Fluorosis level } & \multicolumn{3}{c}{ Caries status } \\
\cline { 2 - 4 } & $\begin{array}{c}\text { Low } \\
(0-3)\end{array}$ & $\begin{array}{c}\text { Moderate } \\
(4-6)\end{array}$ & $\begin{array}{c}\text { High } \\
(>6)\end{array}$ \\
\hline Normal & 761 & 46 & 10 \\
Questionable & 188 & 11 & 1 \\
Very mild & 357 & 26 & 6 \\
Mild & 77 & 6 & 1 \\
Moderate / Severe & 22 & 0 & 0 \\
\hline Total & 1405 & 89 & 18 \\
\hline
\end{tabular}

Not Significant, $P=0.635$

to record the prevalence of dental fluorosis directly. However, the prevalence of diffuse opacities provides an estimate for the prevalence of dental fluorosis. Previous epidemiological surveys had ultilised the Deans Index. Thus comparisons can be made with the present study.

The mouth prevalence for fluorosis considers only definite signs of fluorosis ranging from very mild to the severe form. In the present study the mouth prevalence for dental fluorosis was $32.8 \%$ which is similar to the prevalence observed for Lakota in USA (Table 4). This prevalence is higher than local epidemiological studies $(13,14)$ and some other studies conducted elsewhere (Table 4). However, this finding was much lower than the study conducted in Singapore which utilized the same index (3).

Of all subjects examined for fluorosis in the present study, about $31 \%$ were in the very mild or mild category. The proportion of subjects with moderate and severe fluorosis were low being $1.4 \%$ and $0.1 \%$ respectively (Table 2). This finding is similar to other studies done earlier $(13,24)$. The milder forms of dental fluorosis do not compromise oral health and function, however, more severe forms may be perceived as an aesthetic problem by children, parents and peers $(12,25)$.

The prevalence for dental fluorosis in this study was borderline for public health significance. This was also supported by the analysis which indicate no significant correlation between fluorosis and caries status. This is probably due to the fact that the caries level is generally very low in this population. Additionally, the distribution of fluorosis is skewed towards the very mild and questionable status.

The National data (1) for mean DMFT in Selangor for the 12 -year-old was 1.0 that is slightly less than the 1.1 observed for Klang children in this study. The mean DMFT also appears lower than that recorded in other states of Peninsular Malaysia except for the Federal Territory which was 0.9 . The Malays and Chinese have similar DMFT score of 1.1 whilst Indians have a lower score of 0.9 . Overall the ' $F$ ' component is higher compared to the ' $\mathrm{D}$ ' and the ' $\mathrm{M}$ ' component. Children 
Table 4. Comparison of studies on dental fluorosis based on Dean's Index among 12-13-year-old children.

\begin{tabular}{|c|c|c|c|c|c|c|c|}
\hline Study & $\begin{array}{l}\text { Fluoridation } \\
\text { status of } \\
\text { population (\%) }\end{array}$ & Normal & Questionable & Very mild & Mild & Moderate & Severe \\
\hline Singapore* & 100 & 12.7 & 3.2 & 14.1 & 31.7 & 26.7 & 11.6 \\
\hline Erfurt, Germany ** & Low & 99.0 & 0.2 & 0.4 & 0.3 & 0.1 & 0 \\
\hline Yamanashi, Japan** & Low & 99.0 & 0.5 & 0.2 & 0 & 0 & 0 \\
\hline New Zealand** & 50 & 93.0 & 5 & 2 & 0 & 0 & 0 \\
\hline Lodz, Poland ${ }^{\star *}$ & 0 & 97.0 & 0 & 0.2 & 0 & 0 & 0 \\
\hline Baltimore, USA ${ }^{* *}$ & 82 & 30.0 & 37 & 24 & 7 & 2 & 0 \\
\hline Navajo, USA** & 50 & 10.0 & 14 & 40 & 24 & 10 & 2 \\
\hline Lakota, USA** & 70 & 52 & 11 & 22 & 7 & 7 & 2 \\
\hline Present study & 70 & 54 & 13.2 & 25.7 & 5.6 & 1.4 & 0.1 \\
\hline
\end{tabular}

*Quoted from Lo and Bagramain, 1996

** Quoted from Chen et al, 1997

from urban areas have lower DMFT as compared to rural. However, this geographical difference may be attributed to the higher level of fluoride in drinking water in urban areas and probably an increase awareness on oral health amongst urban children. Hence efforts must be taken to maintain or reduce the level of dental caries nationwide.

In conclusion, although the present study showed that the dental fluorosis level is at a borderline score for public health significance, continued surveillance is required to assess the level of fluorosis. If the prevalence of dental fluorosis increases there is a need for reduction of fluoride in the water supply as it is the most easily controlled source. It is recommended that further study on the relative contribution of fluoride from fluoride in drinking water, toothpaste and diet is needed. This is particularly important because Malaysia is a multi ethnic population with different cultural and dietary habits. New targets for oral health should be established and strategies develop to bring down further the dental caries level among children.

\section{ACKNOWLEDGEMENTS}

The assistance of the school principals and the children's participation is gratefully acknowledged. Financial support was provided by the University of Malaya Grant (PJP 226/90).

\section{REFERENCES}

1. National Oral Health Survey of schoolchildren 1997 (NOHSS '97). Oral Health Division, Ministry of Health, Malaysia 1998.

2. Chen M, Andersen RM, Barmes DE, Leclerq MH, Lyttle CS. Comparing oral health care systems. A Second International Collaborative Study, World
Health Organization, Geneva and Center for Health Administration Studies, The University of Chicago, 1997.

3. Lo GL, Bagramain RA. Prevalence of dental fluorosis in children in Singapore. Community Dent Oral Epidemiol 1996; 24: 25-27.

4. Rozier GR. The pravalence and severity of enamel fluorosis in North American children. J Public Health Dent 1999; 59: 239-246.

5. Villa AE, Guerrero S, Icaza G, Villalobos J, Anabalon M. Dental fluorosis in Chilean children:evaluation of risk factors. Community Dent Oral Epidemiol 1998; 26: 310-315.

6. Vigild M, Skougaard M, Hadi RA, al Zaabi F, al Yaseen I. Dental caries and dental fluorosis among 4-, 6-, 12- and 15-year-old children in kindergartens, and public schools in Kuwait. Community Dent Health, 1996; 13: 47-50.

7. Hawley GM, Ellwood RP, Davies RM. Dental caries, fluorosis and the cosmetic implications of different TF scores in 14-year-old adolescents. Community Dent Health, 1996; 13: 189-192.

8. Epidemiological survey of developmental defects of dental enamel in Johore. 1986. Dental Division, Johore, Malaysia.

9. Majid ZA, Nik Hussein NN, Bagramain RA. The prevalence of caries and developmental defects in an adult population in Malaysia. Dent $\mathrm{J}$ Malaysia 1995; 16: 33-39.

10. Nik Hussein NN, Razak IA. The prevalence of caries and distribution of enamel defects in 11-12 year-old Malaysian schoolchildren. Ann Acad Med Sing 1989; 18: 591-593. 
11. Majid ZA, Nik Hussein NN, Bagramain RA. The prevalence of caries and developmental defects in 229 Malaysian children 16 years after water fluoridation (a pilot study). Sing Dent J 1996; 21:1115 .

12. Sujak SL. Prevalence and aesthetic perception of developmental defects of dental enamel among 16 years-old schoolchildren in Penang. Research report in partial fulfillment for the degree of Master in Community Dentistry, University of N alaya 1997.

13. Dental Division, Ministry of Health. Dental epidemiological survey of schoolchildren in Peninsular Malaysia. 1988. Government Printer, Kuala Lumpur, Malaysia 1989.

14. Dental Division, Ministry of Health. Dental epidemiological survey of schoolchildren in Sabah. July 1985- October 1985. Government Printer, Kuala Lumpur, Malaysia 1986.

15. Razak IA. Changing trends in the pattern of dental caries of 12-year-old schoolchildren between 19791985. Sing Dent J 1986; 1: 11-14.

16. Dental Division, Ministry of Health. Dental epidemiological survey of schoolchildren in West Malaysia: August 1970-May 1971. Government Printer, Kuala Lumpur, Malaysia 1972.

17. Dental Division, Ministry of Health. Dental epidemiological survey of schoolchildren in Sarawak. November 1980- November 1981. Ban Lee Press, Kuching 1982.
18. Dental Division, Sarawak Health Department. Oral health survey of schoolchildren in Sarawak 1994.

19. International Collaborative Study on oral health outcomes (ICS II), Protocol, and Center for Health Administration Studies, The University of Chicago, 1988.

20. Fleiss JL, Fischman SL, Chilton NW, Park MH. Reliability of discrete measurements in caries trials. Caries Res. 1979; 13: 23-31.

21. Burt BA. Methods for assessing the distribution of oral diseases. In Striffler DF, Young WO, Burt BA. Dentistry, Dental Practice \& the Community. $3^{\text {rd }}$ edn. WB Saunders Company 1983; 99-104.

22. Harald AA, Barmes DE, Cohen LK, Hunter PBV, Ship II. Oral Health Care Systems. An International Collaborative Study, World Health Organization. Quintessence Pub. Co. Ltd., 1985.

23. Federation Dentaire International. Commission on Oral Health Research \& Epidemiology. An Epidemiological Index of Developmental Defects of Dental Enamel. Int Dent J 1982; 32: 159-167.

24. Ismail AI, Messer JG, Hornet PJ. Prevalence of dental caries and fluorosis in seven- to 12-year-old children in northern Newfoundland and Forteau, Labrador. J Can Dent Assoc 1998; 64: 118-124.

25. Riordan PJ. Perceptions of dental fluorosis. J Dent Res 1993; 72: 1268-1274. 